Sains Malaysiana 49(2)(2020): 357-373

http://dx.doi.org/10.17576/jsm-2020-4902-14

\title{
Tocotrienol-Rich Fraction Modulates Cardiac Metabolic Profile Changes in Isoprenaline-Induced Myocardial Infarction Rats
}

(Fraksi Kaya Tokotrienol Memodulasi Perubahan Profil Metabolisma Jantung pada Tikus Infarksi Miokardium Aruhan Isoprenalin)

\author{
Khairul Anwar Zarkasi, Satirah Zainalabidin, TAn Jen-Kit, Nur HaleEda HaKimi, Nur Zuliani Ramli \\ \& ZAKIAH JUBRI*
}

ABSTRACT

In myocardial infarction (MI), the occurrence of energy depletion, oxidative stress, and decreased amino acids metabolism alter tissue metabolites. Evidence has shown that tocotrienol-rich fraction (TRF) prevents myocardial injury in MI. However, the protective mechanism at the metabolite level is unknown. Male Sprague-Dawley rats were grouped into control, isoprenaline (ISO)-induced MI (MI), healthy rats receiving $200 \mathrm{mg} / \mathrm{kg}$ TRF (200TRF), and MI rats receiving $200 \mathrm{mg} / \mathrm{kg}$ TRF (200TRF+MI) groups. TRF was administered via oral gavage daily for 12 weeks followed by intraperitoneal ISO injection ( $85 \mathrm{mg} / \mathrm{kg}$ ) for two consecutive days at a 24-hour interval to induce MI. High-performance liquid chromatography was performed to analyze serum $\alpha$-tocopherol and tocotrienol concentration whereas ultrahigh-performance liquid chromatography-mass spectrometry was used for the untargeted metabolomic study. Serum $\alpha$-tocopherol but not tocotrienol was increased in the 200TRF $(p=0.121)$ and 200TRF $+M I(p<0.05)$ following TRF supplementation. Multivariate analysis by Orthogonal Projections to Latent Structures Discriminant Analysis showed high predictability of the group comparison models for MI vs control and 200TRF+MI vS MI (cross-validation: $Q^{2}>0.7$, $R^{2} Y>0.8, p<0.05$ ). A total of 84 and 37 metabolites [when covariance of $p \geq|0.05|$ (magnitude) and $p($ corr $) \geq|0.5|$ (reliability)] were significantly different in the myocardial homogenates of MI vs control and 200TRF $+M I$ vs MI, respectively. MI rats had reduced S-adenosylmethionine and L-cystathionine that might worsen MI by disturbing glutathione metabolism; decreased phosphoribosyl-pyrophosphate and purine salvage process that might impair DNA synthesis, and elevated glucose-6-phosphate suggesting enhanced anaerobic glycolysis possibly for rapid production of energy. Conversely, TRF supplementation reversed the impaired metabolic pathways caused by MI.

Keywords: Isoprenaline; liquid chromatography-mass spectrometry; metabolomics; myocardial infarction; tocotrienolrich fraction

\section{ABSTRAK}

Dalam infarksi miokardium (MI), penurunan tenaga, tekanan oksidatif, serta pengurangan metabolisme asid amino mengubah metabolit dalam tisu. Bukti terkini menunjukkan bahawa fraksi kaya tokotrienol (TRF) mencegah kecederaan miokardium dalam MI. Namun, mekanisme perlindungannya pada tahap metabolit masih tidak diketahui. Tikus Sprague-Dawley jantan dibahagikan kepada kumpulan kawalan, MI aruhan isoprenalin (ISO) (MI), tikus sihat yang menerima $200 \mathrm{mg} / \mathrm{kg}$ TRF (200TRF), dan tikus MI yang menerima $200 \mathrm{mg} / \mathrm{kg}$ TRF (200TRF + MI). TRF diberikan melalui gavaj oral setiap hari selama 12 minggu diikuti suntikan ISO secara intraperitoneum $(85 \mathrm{mg} / \mathrm{kg})$ dua hari berturut-turut berselang 24 jam untuk mengaruh MI. Kromatografi cecair berprestasi tinggi digunakan untuk menganalisis kepekatan serum $\alpha$-tokoferol dan tokotrienol manakala kromatografi cecair berprestasi ultra-tinggi-spektrometri jisim digunakan untuk kajian metabolomik tanpa sasaran. Serum $\alpha$-tokoferol tetapi tidak tokotrienol telah meningkat bagi kumpulan 200TRF $(p=0.121)$ dan 200TRF+MI $(p<0.05)$ setelah disuplementasi TRF. Analisis multivariat oleh Unjuran Ortogon kepada Analisis Diskriminasi Struktur Pendam menunjukkan kebolehramalan yang tinggi bagi model perbandingan antara kumpulan MI vs kawalan dan 200TRF + MI vs MI (pengesahan silang: $Q^{2}>0.7, R^{2} Y>0.8, p<0.05$ ). Sebanyak 84 dan 37 metabolit [apabila kovarians $p \geq|0.05|$ (magnitud) dan $p($ corr $) \geq|0.5|$ (kebolehpercayaan)] berbeza secara signifikan dalam homogenat miokardium masing-masing bagi kumpulan MI vs kawalan dan 200TRF+MI vs MI. Tikus MI mengalami penurunan S-adenosilmetionina dan L-sistationina yang mungkin meningkatkan keterukan MI melalui gangguan metabolisme glutation; pengurangan fosforibosil-pirofosfat dan proses penyelamatan purina yang mungkin menjejaskan sintesis DNA, serta peningkatan glukosa-6-fosfat bagi proses glikolisis anaerob yang mungkin bertujuan menghasilkan tenaga secara pantas. Sebaliknya, suplementasi TRF menghalang penjejasan pada laluan metabolisma yang dicetuskan oleh MI.

Kata kunci: Fraksi kaya tokotrienol; infarksi miokardium; isoprenalin; kromatografi cecair-spektrometri jisim; metabolomik 


\section{INTRODUCTION}

Myocardial infarction (MI) is defined as clinical evidence of myocardial necrosis due to reduced oxygen supply to the heart (Thygesen et al. 2012). It is a part of a disease spectrum known as ischemic heart disease or coronary heart disease that causes $12.3 \%$ of total global deaths, translated to about 7.2 million deaths annually (Finegold et al. 2013; Sanchis-Gomar et al. 2016; World Health Organization 2017). Patients suffering from MI are becoming increasingly younger especially in some developing countries where it affects people aged 55-59 years, in contrast to males aged 63-68 years and females aged 73-79 years in the developed countries (Institute of Medicine 2010; Seong \& John 2016). Being one of the commonest causes of death combined with its high mortality and morbidity rate, the disease impacts not only the individuals who suffer from it, but also to the nation in terms of the overall productivity as well as financial burden in order to provide medical centers with adequate resources for the disease treatment (Che-Muzaini \& Norsa'adah 2017; Lee et al. 2017).

High morbidity and mortality rates associated with MI has prompted extensive studies globally. To understand various aspects of the disease including identifying potential new treatment, several experimental animal models have been developed, including induction method via isoprenaline (ISO) administration through parenteral route (Murugesan et al. 2011; Panda et al. 2017). This is one of the most easily accessible, validated and commonly used technique to induce MI in rats. Also known as isoproterenol, ISO is a sympathomimetic agent that acts exclusively on $\beta$-adrenergic receptors with very little action on $\alpha$-adrenergic receptors. Given the high $\beta$-adrenergic receptor expression in myocardial tissue (MIMS 2019), ISO administration produced significant effects on the heart. ISO causes positive chronotropism and inotropism which increase the rate as well as the force of cardiac contraction. However, it has no effect on $\alpha$-receptors resulting in coronary arterial vasodilation that leads to hypotension in the coronary vascular bed. Cumulatively, ISO increases cardiac output and reduces diastolic as well as mean arterial pressure resulting in oxygen supply and demand mismatch leading to hypoxia (Biaggiono \& Robertson 2014). Exposure to higher doses of ISO leads to ischemia with subsequent MI due to changes in various physiological processes in the myocardium including decreased global adenosine triphosphate (ATP) synthesis, increased oxidative damage, inflammation, and activation of apoptotic pathways along with cell necrosis (Liu et al. 2013; Siddiqui et al. 2016).

Untargeted metabolomics is the study of global metabolic profile in a biological system whereby all the low molecular weight compounds or metabolites that are present and participate in biochemical reactions at a certain time point will be captured and quantified (Horgan \& Kenny 2011). Alterations of the metabolome are the endresult of a series of changes that occur in the genomic, transcriptomic as well as proteomic levels. Metabolic profile can be influenced by diseases, lifestyle and dietary habit, along with other environmental factors such as exposure to pollutants and intake of medications (ClarkMatott et al. 2015; Huang et al. 2014; Riera-Borrull et al. 2017; Viana et al. 2016; Vlaanderen et al. 2017). Thus, studies that utilize metabolomic-based approach would provide insight regarding the overall molecular mechanisms of disease progression and how a therapeutic agent works at the metabolic level. Several authors have reported on the metabolic profile changes in MI by using biological samples from serum, plasma or myocardial tissue homogenate. By comparing MI rats with healthy controls, a number of altered biochemical pathways has been reported including $\beta$-oxidation of fatty acid, metabolism of amino acids such as glycine, serine, arginine and proline, and glycerophospholipid metabolism, among many others (Liu et al. 2013).

Recently, there have been increasing interests toward natural products in combating MI either to be used as preventive strategies or as an adjunct to the current pharmacological therapies. Cardioprotective effects of vitamin $E$ have been discovered and studied for many years in both pre-clinical and clinical fields that show its promising future in the management of MI (Zarkasi et al. 2019). Vitamin E is a general term used to describe naturally occurring compounds that share similar chemical structures and functions comprising several isomers of tocopherols and tocotrienols (Atia \& Abdullah 2014). Many evidence suggests that tocotrienol is more powerful than tocopherol. For instance, the former provides a better anti-aging effect than the latter on senescent myoblasts (Khor et al. 2016). Furthermore, it possesses stronger antiinflammatory and antioxidant properties compared to tocopherol which may be contributed by its higher rate of cellular uptake as well as more uniform distribution in the plasma membrane (Fairus et al. 2006; Maniam et al. 2008; $\mathrm{Ng} \&$ Ko 2012; Serbinova et al. 1991). Tocotrienol is present in foods of plant origin and it is most abundant in rice bran, palm oil and annatto seed (Kannappan et al. 2012). Tocotrienol-rich fraction (TRF) can be obtained from serial processes of esterification, distillation, and concentration of its plant source (Top \& Gapor 2005). It has been observed to reverse MI-related findings such as increased lactate dehydrogenase as well as aspartate and alanine aminotransferases in rat model attributing the effects toward its antioxidant property as well as its ability in stabilizing the proteasome (Bardhan et al. 2015; Das et al. 2008). Additionally, TRF at the dose of $200 \mathrm{mg} / \mathrm{kg} / \mathrm{day}$ was reported to significantly decrease serum creatine kinase-myocardial band, which is a specific marker for myocardial injury, in ISO-induced MI rats (Zainalabidin et al. 2018). However, the cardioprotective mechanism of TRF on MI at the metabolic level is still unknown.

Therefore, the aim of this study was to determine the changes in metabolic profile caused by TRF on rats with ISO-induced MI. 


\section{MATERIALS AND METHODS}

\section{TREATMENT OF ANIMALS AND COLLECTION OF SAMPLES}

Male Sprague-Dawley rats ( $\mathrm{n}=24)$ weighed 250-300 g were purchased from the Laboratory Animal Research Unit, Universiti Kebangsaan Malaysia (UKM) while ethical approval was obtained from the UKM Animal Ethics Committee (approval no. BIOK/PP/2018/ZAKIAH/23JAN./893-JAN.-2018-DEC.-2018-NAR-CAT2). They were kept in a well-ventilated room inside individual cages and were maintained at $25 \pm 3^{\circ} \mathrm{C}$, humidity of $40-60 \%$ with 12 $\mathrm{h}$ light/dark cycle.

The rats were allowed to acclimatize for the first seven days prior to the commencement of the experiment following which they were randomly assigned into four groups ( $\mathrm{n}=6$ per group); control, MI, 200TRF, and 200TRF+MI. Rats from all groups were given normal chow diet with access to tap water ad libitum. Supplementation of TRF (TRF Gold Tri.E 70, Sime Darby Research Sdn. Bhd., Klang, Selangor, Malaysia) at the dose of $200 \mathrm{mg} / \mathrm{kg}$ /day was administered to 200TRF and 200TRF+MI groups via oral gavage for 12 weeks. The TRF Gold Tri.E 70 contains $79.18 \%$ tocotrienol (that includes $\alpha$-tocotrienol, $\beta$-tocotrienol, $\gamma$-tocotrienol, and $\delta$-tocotrienol at $26.76 \%, 4.29 \%$, $32.60 \%$, and $15.53 \%$, respectively) as well as $20.81 \%$ $\alpha$-tocopherol. The amount of different vitamin $\mathrm{E}$ isomers for each gram of TRF are $205.1 \mathrm{mg} \alpha$-tocotrienol, $32.9 \mathrm{mg} \beta$-tocotrienol, $249.8 \mathrm{mg} \gamma$-tocotrienol, $119 \mathrm{mg}$ $\delta$-tocotrienol, and $159.5 \mathrm{mg} \alpha$-tocopherol. At the end of the study period, $85 \mathrm{mg} / \mathrm{kg} /$ day ISO was injected intraperitoneally to group MI and 200TRF+MI during the final two consecutive days with $24 \mathrm{~h}$ interval for MI induction (Madhesh \& Vaiyapuri 2012; Madhesh et al. 2011). The MI model has been validated in the previous study (Satirah et al 2018). ISO was replaced with normal saline for control and 200TRF groups. After two days, the rats were fasted overnight and anesthetized with intravenous KTX (ketamine, zoletil-50 and xylazine mixture) the following day. Blood samples were collected via retro-orbital sinus puncture and the rats were sacrificed via cervical dislocation.

Blood samples that were collected into plain tubes were allowed to clot for 15-30 min and centrifuged at 4,000 rpm for $30 \mathrm{~min}$ while maintaining the temperature at $4^{\circ} \mathrm{C}$. The supernatant (serum) was aliquoted to a new tube at $0.5 \mathrm{~mL}$ each. The hearts were dissected, and left ventricles were harvested for metabolomic analysis. Sera and ventricular tissues were stored at $-80^{\circ} \mathrm{C}$ until further processing.

\section{MEASUREMENT OF SERUM A-TOCOPHEROL AND TOCOTRIENOL CONCENTRATION}

\section{Serum Sample Preparation}

Sample preparation was performed according to Khan et al. (2010) with some modification. Briefly, serum samples were added with butylated hydroxytoluene (SigmaAldrich, St. Louis, MI, USA) to reduce oxidation of the analyte of interest followed by addition of $100 \%$ ethanol (Merck, Darmstadt, Germany) for deproteinization. Liquid-liquid extraction was performed by vortexing the mixture followed by separation via centrifugation at 5,000 rpm for 15 min while maintaining the temperature at $18^{\circ} \mathrm{C}$. The supernatant was transferred to a new tube, mixed with n-hexane (Merck) and vortexed, resulting in a formation of three different layers from which the uppermost layer was collected and vacuum dried for $40 \mathrm{~min}$. The dried sample was reconstituted with $n$-hexane and filtered through $0.2 \mu \mathrm{m}$ regenerated cellulose membrane syringe filter (Minisart RC4, Sartorius Stedim Biotech, Göttingen, Germany) to remove impurities before it was injected into the high-performance liquid chromatography (HPLC) system for analysis.

\section{HPLC System}

All solvents used for determination of serum $\alpha$-tocopherol and tocotrienol were HPLC-grade. Normal phase liquid chromatography was performed on a Shimadzu LC-10AT VP HPLC system controlled by Shimadzu Class-VP (version 6.0) software (Shimadzu, Kyoto, Japan). Chromatographic separation was performed on Luna ${ }^{\circledR}$ Silica (2) column, 250 $\mathrm{mm}$ length $\times 4.6 \mathrm{~mm}$ diameter, particle size $5 \mu \mathrm{m}$ (Phenomenex, Torrance, CA, USA) with the column oven temperature maintained at $30^{\circ} \mathrm{C}$ while the injection volume was $20 \mu \mathrm{L}$. The mobile phase consisted of a mixture between n-hexane and isopropanol (Merck) at 99:1 ratio with a flow rate of $1.5 \mathrm{~mL} / \mathrm{min}$ under $38 \mathrm{kgf} / \mathrm{cm}^{2}$ of pressure. Analyte detection was performed by fluorescence detector when the excitation and emission wavelengths were set at 294 and $330 \mathrm{~nm}$, respectively. Results obtained for each sample were compared to a standard curve for the determination of serum $\alpha$-tocopherol and tocotrienol concentration (Jaafar et al. 2018).

\section{METABOLOMIC ANALYSIS FROM} HEART HOMOGENATE

\section{Myocardial Tissue Sample Preparation}

Myocardial tissue sample preparation was performed according to Marney et al. (2013) with some modifications. Briefly, the myocardial sample of the left ventricle was frozen with liquid nitrogen and crushed. For every $10 \mathrm{mg}$ of heart tissue, $500 \mu \mathrm{L}$ of chilled $80 \%$ methanol (Fischer Scientific, Hampton, NH, USA) was added followed by homogenization with a sonicator at $30 \mathrm{amp}$ while on ice. Once homogenized, the sample was mixed with $300 \mu \mathrm{L}$ chilled chloroform and centrifuged at $20,000 \times g$ at $4{ }^{\circ} \mathrm{C}$ for $10 \mathrm{~min}$. The supernatant was collected and vacuum dried. For every $10 \mathrm{mg}$ of heart tissue used, $200 \mu \mathrm{L}$ of $20 \%$ methanol was added to reconstitute the dried sample. The mixture was filtered to remove impurities before it was injected into the ultra-high-performance liquid chromatography-mass spectrometry (UHPLC-MS) system for analysis. 
UHPLC-Orbitrap MS System

All solvents for metabolomic analysis were MS-grade. Liquid chromatography was performed on UHPLC Dionex UltiMate $^{\mathrm{TM}} 3000$ Rapid Separation System coupled with Q Exactive $^{\mathrm{TM}}$ HF hybrid quadrupole-Orbitrap mass spectrometer (Thermo Fischer Scientific) containing heated electrospray ionization probe (HESI-II). The system was controlled by Chromeleon Xpress and MS Thermo Xcalibur $^{\mathrm{TM}}$ (version 4.0) system data. Chromatographic separation was performed by using reversed phase Syncronis $^{\mathrm{TM}}$ C18 column, $100 \mathrm{~mm}$ length $\times 2.1 \mathrm{~mm}$ diameter, particle size $1.7 \mu \mathrm{m}$ (Thermo Scientific) maintained at $55^{\circ} \mathrm{C}$ with an injection volume of $2 \mu \mathrm{L}(\mathrm{n}=3$ samples with 3 technical replicates for each sample).

Samples were randomly injected into the system while maintaining automatic sampler temperature at $10^{\circ} \mathrm{C}$. The flow rate of the solvents was set at $0.45 \mathrm{~mL} / \mathrm{min}$ using Optima $^{\circledR}$ ultrapure water (Fischer Scientific) as mobile phase A and acetonitrile (Fischer Scientific) as mobile phase B where both contained $0.1 \%(\mathrm{v} / \mathrm{v})$ formic acid (Thermo Fischer Scientific). Elution gradient program for $15 \mathrm{~min}$ was set as followed: $0 \mathrm{~min}, 0.5 \% \mathrm{~B} ; 5.5 \mathrm{~min}, 50 \%$ B; 6-12 min, 98\% B; 13-15 min, 0.5\% B. Positive and negative ionization modes were performed under these conditions: Sheath gas flow rate at 50 arbitrary unit (AU), auxiliary gas flow rate at $18 \mathrm{AU}$, sweep gas flow rate at 0 $\mathrm{AU}$, capillary temperature at $320^{\circ} \mathrm{C}$ and spray voltage of $3.5 \mathrm{kV}$ for positive mode or $3.0 \mathrm{kV}$ for negative mode. MS spectra were obtained using full MS/data-dependent MS2 (TopN) (dd-MS2) by which MS2 was triggered when highintensity ion was discovered in full MS scan. Full MS scan parameters include: Default charge state of 1, resolution of 60,000, automatic gain control (AGC) of $1 \mathrm{e} 6$, maximum injection time (IT) of $120 \mathrm{~ms}$, and a scan range between $100-1,000 \mathrm{~m} / \mathrm{z}$.

Parameters for dd-MS2 scan were as followed: resolution of 15,000, AGC target of 5e4, maximum IT set at $50 \mathrm{~ms}$, loop count of 5, TopN of 5, isolation window of $1.5 \mathrm{~m} / \mathrm{z}$, and stepped normalized collision energy at 20, 40 and 60. Settings for the dd include: Minimum AGC target of $8 \mathrm{e} 2$, intensity threshold at 1.6e4, exclude isotope 'on', and dynamic exclusion at $10 \mathrm{~s}$. The MS system was calibrated by using Pierce LTQ ESI Positive Ion and Pierce LTQ ESI Negative Ion Calibration Solutions (Thermo Scientific). For quality control (QC), an aliquot of equal volume $(2 \mu \mathrm{L})$ from each sample was pooled and mixed in a separate vial labeled as QC sample to assess the reproducibility and reliability of the LC-MS/MS system. The pooled QC sample was injected thrice prior to analysis of the individual sample and was repeated after every sixth sample injection.

\section{Data Pre-processing}

The data file '.RAW' was processed with Thermo Scientific Compound Discoverer ${ }^{\mathrm{TM}} 2.0$ (CD 2.0) software using untargeted workflow. This workflow used 'Detect Unknown Compounds' node to find chromatographic peaks for unknown compounds [molecular weight $(\mathrm{m} / \mathrm{w}) \times$ retention time (RT)] and 'Predict Composition' node to determine possible compositions of the elements that formed the compounds. Additionally, the workflow performed searches in mzCloud and ChemSpider databases to annotate unknown compounds that have been detected by the LC-MS system (Figure 1). This pre-processed data was then exported to the '.xlsx' file for subsequent statistical analysis.

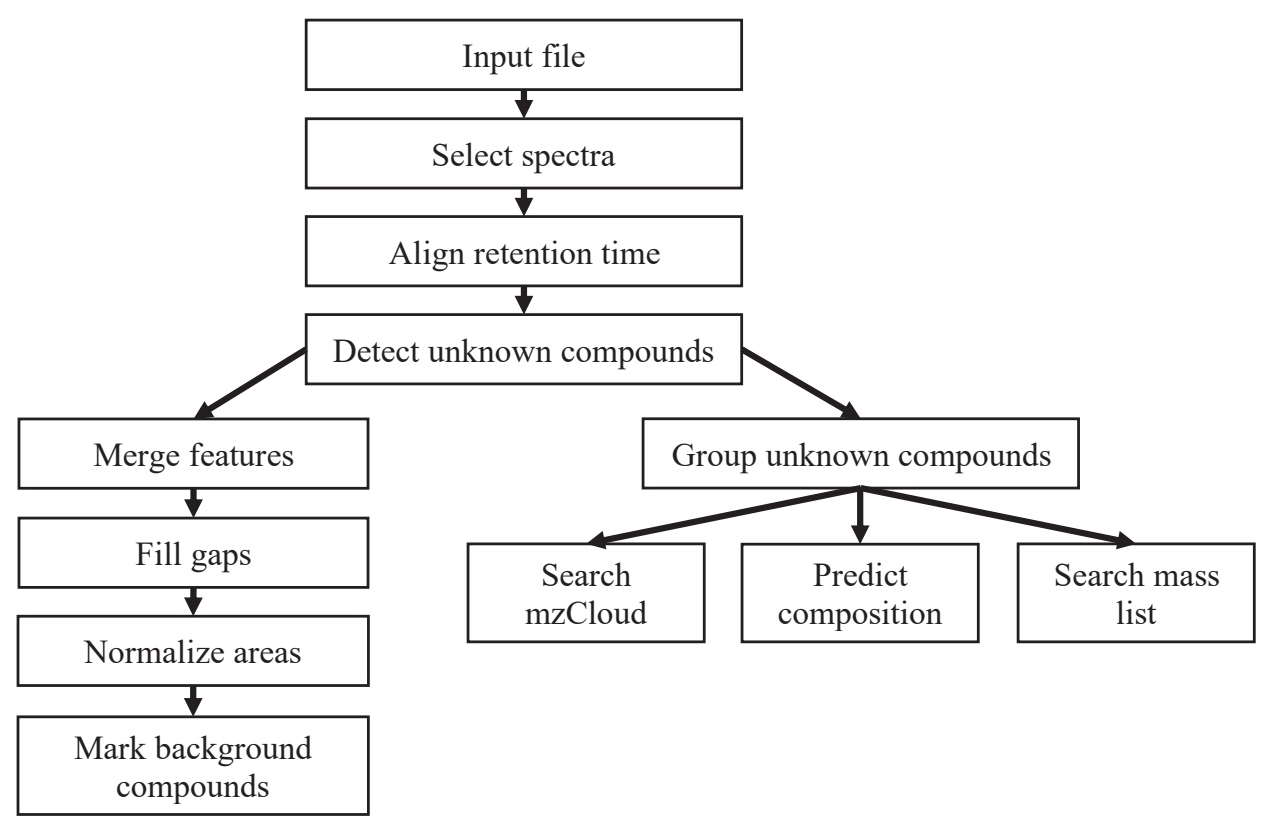

FIGURE 1. Workflow for data pre-processing in Thermo Scientific Compound DiscovererTM 2.0 (CD 2.0) whereby 'Untargeted Metabolomic Analysis with Statistics' approach was used followed by database search in mzCloud and ChemSpider to annotate the detected unknown compounds 
Multivariate Analysis

The peak areas for the detected metabolites were analyzed using the 'Statistical Analysis' module in MetaboAnalyst 4.0 online software (Chong et al. 2018). The data was preprocessed by subjecting to normalization processes that include quantile normalization to make the data distribution for different groups more identical, cube root transformation to adjust the data distribution toward normal distribution, and mean centering to eliminate offset data and focus on differences rather than similarities for each variable.

Unsupervised Principal Component Analysis (PCA) and supervised Orthogonal Projections to Latent Structures Discriminant Analysis (OPLS-DA) were used as multivariate analytical methods. In OPLS-DA, the covariance between $\mathrm{X}$ and $\mathrm{Y}$ had been maximized to identify which metabolites were responsible for separation between different rat groups. Furthermore, permutation test was done to assess the statistical significance of group separations with $p$-value set at $\leq 0.05$. Differentially expressed metabolites (DEMs) were then selected if their covariance of $p \geq|0.05|$ (magnitude) and $p$ (corr) $\geq|0.5|$ (reliability) on $\mathrm{S}$ plot of OPLS-DA (Jung et al. 2010; Suvagandha et al. 2014).

\section{Metabolites Annotation}

DEMs were annotated by cross-referencing the Human Metabolome Database (HMDB) (http://www.hmdb.ca/) and Metlin Library database (https://metlin.scripps.edu/) with mass accuracy set at $5 \mathrm{ppm}$ (Durani et al. 2017). MS/MS spectra of putative metabolites were also compared with the online mzCloud database linked to CD 2.0 software or on its website (https://www.mzcloud.org/) before they were used for further analysis. Additionally, fold change analysis was also performed by comparing 'MI $v s$ control' and '200TRF+MI vs MI' to determine the fold changes for these metabolites.

\section{Pathway Analysis}

Annotated DEMs were subsequently analyzed by using the 'Pathway Analysis' module in the MetaboAnalyst 4.0 software to obtain a clearer picture of the disturbed biochemical pathways in ISO-induced MI rats and the metabolic pathways changes following TRF supplementation in MI. For the mapping process, the metabolite library for Rattus norvegicus had been selected. The algorithm for pathway analysis was performed by applying the 'Fischer exact test' for over-representational analysis while 'relative-betweenness centrality; was selected for the analysis of the pathway topology. Metabolic pathways with impact-values $>0.1$ were considered to be relevant (Durani et al. 2017)

\section{STATISTICAL ANALYSIS}

Data for serum $\alpha$-tocopherol and tocotrienol was analyzed by using IBM Statistical Package for the Social Sciences $\left(\right.$ SPSS $^{\circledR}$ ) (version 23.0). Since the data distribution was skewed, central tendency and dispersion were expressed in median and interquartile range (IQR) while differences among groups were assessed by using non-parametric techniques.

\section{RESULTS AND DISCUSSION}

\section{EFFECTS OF TRF ON SERUM A-TOCOPHEROL AND TOCOTRIENOL CONCENTRATION}

Measurement of serum $\alpha$-tocopherol and tocotrienol concentrations was performed at the beginning and at the end of the study period. There was no difference for serum $\alpha$-tocopherol among all rat groups at baseline. Supplementation with TRF was found to increase the serum $\alpha$-tocopherol levels for 200TRF and 200TRF+MI rats at week 12 compared to the same group at baseline (Figure 2(A)). Additionally, serum $\alpha$-tocopherol for the 200TRF+MI group was significantly higher than MI rats with respective median (IQR) of $25.42 \mu \mathrm{g} / \mathrm{mL}(20.7-40.5 \mu \mathrm{g} / \mathrm{mL})$ and 14.17 $\mu \mathrm{g} / \mathrm{mL}(12.6-17.6 \mu \mathrm{g} / \mathrm{mL})(p<0.05)$. Supplementation of TRF produced a similar elevation of serum $\alpha$-tocopherol in the 200TRF compared to control rats by $91.1 \%$ although the change was statistically insignificant $(p=0.121$ ). On the other hand, serum tocotrienol was similar at baseline for all rat groups. Supplementation with TRF for 12 weeks did not cause any change in the serum tocotrienol concentrations for 200TRF and 200TRF+MI compared to the same groups
(A)

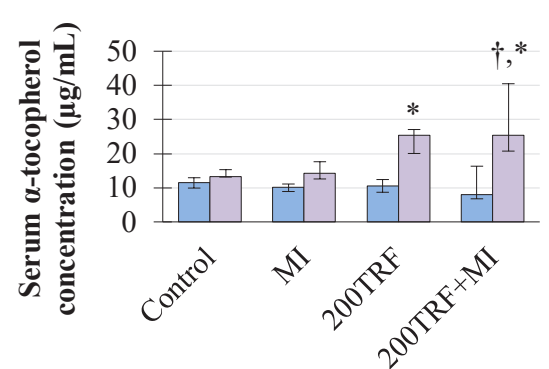

(B)



FIGURE 2. Changes in the serum $\alpha$-tocopherol (A) and tocotrienol (B) concentrations ( $\mu \mathrm{g} / \mathrm{mL}$ ) at baseline and week 12 . Values are shown in median, error bars represent interquartile range (IQR). * Significantly differed from the same group at baseline with $\mathrm{p}<0.05$. $\dagger$ Significantly differed from the MI group at week 12 with $\mathrm{p}<0.05$. Abbreviations: MI (ISO-induced MI rats), 200TRF (healthy rats receiving $200 \mathrm{mg} / \mathrm{kg} /$ day TRF); 200TRF+MI (ISO-induced rats receiving $200 \mathrm{mg} / \mathrm{kg} / \mathrm{day}$ TRF) 
at baseline. Similarly, serum tocotrienol levels did not differ between 200TRF and control as well as between 200TRF+MI and MI groups at the end of the study period (Figure 2(B)).

These findings could be explained by the differences in biological processes involving transport and bioavailability of vitamin $\mathrm{E}$ within the blood circulation. Firstly, supplementation of vitamin E maximally increases the blood level of tocopherol and tocotrienol at a different time point. Administration of TRF orally in human subjects caused plasma $\alpha$-tocotrienol to reach peak concentration earlier than $\alpha$-tocopherol, recorded at about $4 \mathrm{~h}$ and $6 \mathrm{~h}$, respectively. Additionally, post-prandial elevation of plasma $\alpha$-tocotrienol was still significantly lower than $\alpha$-tocopherol with a mean concentration of $4.79 \pm 1.2 \mu \mathrm{g} /$ $\mathrm{mL}$ for the former and $13.46 \pm 1.68 \mu \mathrm{g} / \mathrm{mL}$ for the latter (Fairus et al. 2006). Thus, findings on serum $\alpha$-tocopherol and tocotrienol in this study might be affected by the differences in the bioavailability for both vitamin $\mathrm{E}$ vitamers.

Secondly, cellular uptake is higher for tocotrienol as compared to tocopherol. In a study using Jurkat cell line E6-1, $\alpha$-tocotrienol reportedly entered the cell 70 times faster than $\alpha$-tocopherol (Saito et al. 2004). As a result, tocotrienol might be subjected to higher clearance from blood circulation. Therefore, no differences were observed in the plasma tocotrienol concentration in rats receiving TRF supplementation compared to non-supplemented groups in the current study.

Thirdly, different protein carriers have different affinity for vitamin E vitamers and might affect its blood concentration. Majority of dietary vitamin $\mathrm{E}$ is transported by lipoproteins to reach peripheral tissues. However, the observed amount of tocopherols were higher than tocotrienols in chylomicron, low-density lipoprotein as well as high-density lipoprotein which stood at approximately $21 \%, 58 \%$ and $45 \%$, respectively (Fairus et al. 2012). In addition, there is a special protein carrier for tocopherol transport in the blood circulation, especially for $\alpha$ and $\gamma$-isomers. It is an albumin protein family known as afamin (Dieplinger \& Dieplinger 2015). Simulation study performed on the predicted tertiary structure of afamin found that the protein had 18 different binding sites for tocopherol alone (Voegele et al. 2002).

The explained mechanisms might lead to higher blood tocopherol level as compared to tocotrienol. Subsequently, any changes in relation to its concentration could be easily and clearly detected. Further study is needed to measure the level of vitamin $\mathrm{E}$ in the cardiac tissue for a better understanding of the relationship between bioavailability and efficacy of the cardioprotective effect of TRF.

\section{METABOLIC PATHWAY CHANGES IN THE MYOCARDIAL TISSUE OF RATS WITH MI AND THE EFFECTS OF TRF SUPPLEMENTATION}

Initial analysis by the PCA showed incomplete separation between MI and control groups, between 200TRF and control groups as well as between 200TRF+MI and MI groups. Therefore, multivariate analysis using OPLS-DA was performed to maximize the separation and to identify important metabolites that were responsible for the differences between those groups. OPLS-DA resulted in a clear separation between MI and control groups as well as between 200TRF+MI and MI groups but not between 200TRF and control rats (Figure 3). Permutation tests for $Q^{2}$ and $R^{2} Y$ were statistically significantly different for the comparisons between MI and control groups as well as between 200TRF+MI and MI groups, suggesting that these

TABLE 1. Permutation test and cross-validation results for Orthogonal Projections to Latent Structures Discriminant Analysis (OPLS-DA)

\begin{tabular}{lccccc}
\hline Groups & ESI & Q2 & p-Value Q2 & R2Y & p-Value R2Y \\
\hline \multirow{2}{*}{ MI vs control } & + & 0.752 & $<0.0005^{*}$ & 0.891 & $0.0265^{*}$ \\
& - & 0.891 & $<0.0005^{*}$ & 0.998 & $<0.0005^{*}$ \\
\multirow{2}{*}{ 200TRF vs control } & + & 0.230 & $0.0430^{*}$ & 0.385 & 0.3680 \\
& - & 0.353 & $0.0160^{*}$ & 0.491 & 0.2055 \\
200 TRF+MI vs MI & + & 0.819 & $<0.0005^{*}$ & 0.951 & $0.0005^{*}$ \\
& & 0.731 & $0.0010^{*}$ & 0.993 & $0.0065^{*}$ \\
\hline
\end{tabular}

*Statistically significant when $\mathrm{p}<0.05$ in permutation test. Abbreviation: ESI (electrospray ionization). Cross-validation: Q2 $=$ quality assessment, $\mathrm{R} 2 \mathrm{Y}=\mathrm{degree}$ of fit to the data

TABLE 2. The number of differentially expressed metabolites (DEMs) between different group comparisons

\begin{tabular}{|c|c|c|c|c|c|}
\hline \multirow{2}{*}{ Groups } & \multicolumn{2}{|c|}{ DEMs } & \multirow[b]{2}{*}{ Total } & \multirow[b]{2}{*}{ Annotated } & \multirow[b]{2}{*}{ Unannotated } \\
\hline & ESI (+) & ESI (-) & & & \\
\hline MI vs control & 150 & 40 & 190 & 84 & 106 \\
\hline $200 \mathrm{TRF}+\mathrm{MI}$ vs MI & 69 & 16 & 85 & 37 & 48 \\
\hline
\end{tabular}

ESI $=$ electrospray ionization 
TABLE 3. List of annotated DEMs in between MI and control group

\begin{tabular}{|c|c|c|c|c|}
\hline \multicolumn{5}{|c|}{ MI vs control } \\
\hline $\mathrm{m} / \mathrm{w}$ & Putative Metabolites & Identifiers & ESI & $\mathrm{FC}$ \\
\hline 129.04280 & 5-Oxoproline & HMDB0060262 & + & $\uparrow 14.26$ \\
\hline 163.12104 & Acetylcysteine & $\wedge 511$ & + & $\uparrow 2.06$ \\
\hline 280.10608 & Phenylalanyl-aspartate & HMDB0028991 & + & $\uparrow 1.98$ \\
\hline 168.02847 & Uric acid & HMDB0000289 & + & $\uparrow 1.69$ \\
\hline 393.86701 & 2-(14,15-Epoxyeicosatrienoyl) glycerol & $\wedge 4758$ & + & $\downarrow 1.46$ \\
\hline 252.00116 & 2'-Deoxyinosine & $\wedge 1187$ & + & $\downarrow 1.45$ \\
\hline 459.35185 & 5-Methyltetrahydrofolic acid & $\wedge 262$ & + & $\downarrow 1.30$ \\
\hline 297.08974 & 5'-Methylthioadenosine & HMDB0001173 & + & $\downarrow 1.24$ \\
\hline 340.27968 & $\alpha$-D-Glucose-1,6-bisphosphate & $\wedge 1711$ & + & $\downarrow 1.41$ \\
\hline 335.31899 & $\beta$-Nicotinamide mononucleotide & $\wedge 871$ & + & $\downarrow 1.75$ \\
\hline 260.13719 & $\gamma$-Glutamyl-L-isoleucine & *62019 & + & $\downarrow 1.16$ \\
\hline 299.07701 & D-4'-Phosphopantothenate & HMDB0001016 & + & $\downarrow 1.53$ \\
\hline 429.90703 & D- $\alpha$-Tocopherol & $\wedge 328$ & + & $\downarrow 2.01$ \\
\hline 159.12609 & DL-2-Aminooctanoic acid & HMDB0000991 & + & $\downarrow 1.98$ \\
\hline 219.99107 & L-5-Hydroxytryptophan & $\wedge 254$ & + & $\downarrow 1.38$ \\
\hline 204.11107 & L-Acetylcarnitine & $\wedge 879$ & + & $\downarrow 1.07$ \\
\hline 186.11880 & L-Alanyl-L-proline & $\wedge 461$ & + & $\downarrow 1.35$ \\
\hline 240.13492 & L-Anserine & $\wedge 1308$ & + & $\downarrow 1.69$ \\
\hline 267.97498 & L-Homocysteine & $\wedge 476$ & + & $\downarrow 1.42$ \\
\hline 149.05120 & L-Methionine & HMDB0000696 & + & $\downarrow 1.78$ \\
\hline 117.07926 & L-Valine & HMDB0000883 & + & $\downarrow 1.27$ \\
\hline 115.06368 & L-Proline & HMDB0000162 & + & $\downarrow 1.40$ \\
\hline 309.10605 & N-Acetylneuraminic acid & $\wedge 1249$ & + & $\downarrow 1.46$ \\
\hline 217.13166 & O-Propanoylcarnitine & HMDB0062514 & + & $\downarrow 2.08$ \\
\hline 181.07400 & o-Tyrosine & HMDB0006050 & + & $\downarrow 1.50$ \\
\hline 206.04355 & (R)-Lipoic acid & HMDB0001451 & + & $\downarrow 1.05$ \\
\hline 399.37128 & S-Adenosylmethionine & $\wedge 896$ & + & $\downarrow 1.20$ \\
\hline 425.35075 & Acylcarnitine C18:1 & HMDB0005065 & + & $\downarrow 1.26$ \\
\hline 135.06165 & Adenine & 296 & + & $\downarrow 1.54$ \\
\hline 267.09692 & Adenosine & 297 & + & $\downarrow 2.00$ \\
\hline 226.10675 & Carnosine & HMDB0000033 & + & $\downarrow 1.01$ \\
\hline 483.46558 & Cer(d18:0/12:0) & HMDB0011758 & + & $\downarrow 1.22$ \\
\hline 511.49656 & Cer(d18:0/14:0) & HMDB0011759 & + & $\downarrow 1.22$ \\
\hline 539.52779 & $\operatorname{Cer}(\mathrm{d} 18: 0 / 16: 0)$ & HMDB0011760 & + & $\downarrow 1.24$ \\
\hline 567.55941 & Cer(d18:0/18:0) & HMDB0011761 & + & $\downarrow 1.21$ \\
\hline 595.59105 & $\operatorname{Cer}(\mathrm{d} 18: 0 / 20: 0)$ & HMDB0011764 & + & $\downarrow 1.29$ \\
\hline 555.52319 & $\operatorname{Cer}(\mathrm{t} 18: 0 / 16: 0)$ & HMDB0010697 & + & $\downarrow 1.22$ \\
\hline 243.08565 & Cytidine & HMDB0000089 & + & $\downarrow 1.57$ \\
\hline 347.06327 & Deoxyguanosine 5'-monophosphate & HMDB0001044 & + & $\downarrow 1.60$ \\
\hline 307.56758 & Deoxyuridine monophosphate (dUMP) & $\wedge 1196$ & + & $\downarrow 1.42$ \\
\hline 450.34634 & Geranylgeranyl pyrophosphate & $\wedge 1288$ & + & $\downarrow 1.37$ \\
\hline 188.11630 & Glycyl-L-leucine & $\wedge 430$ & + & $\downarrow 1.51$ \\
\hline 283.09183 & Guanosine & HMDB0000133 & + & $\downarrow 2.27$ \\
\hline
\end{tabular}




\begin{tabular}{|c|c|c|c|c|}
\hline 247.14209 & Hydroxybutyrylcarnitine & HMDB0013127 & + & $\downarrow 4.23$ \\
\hline 507.57505 & Inosine triphosphate & $\wedge 1236$ & + & $\downarrow 1.06$ \\
\hline 228.14756 & Leucylproline & $\wedge 468$ & + & $\downarrow 2.26$ \\
\hline 453.28596 & Lysophosphatidylethanolamine(16:0) & HMDB0011473 & + & $\downarrow 1.40$ \\
\hline 479.30161 & Lysophosphatidylethanolamine(18:1) & HMDB0011476 & + & $\downarrow 2.24$ \\
\hline 529.31731 & Lysophosphatidylethanolamine(22:4) & HMDB0011493 & + & $\downarrow 3.81$ \\
\hline 525.28588 & Lysophosphatidylethanolamine(22:6) & HMDB0011496 & + & $\downarrow 1.35$ \\
\hline 121.91751 & Nicotinamide (niacinamide) & $\wedge 517$ & + & $\downarrow 1.31$ \\
\hline 122.58708 & Nicotinic acid & $\wedge 519$ & + & $\downarrow 1.26$ \\
\hline 132.02470 & Oxaloacetic acid & $\wedge 1353$ & + & $\downarrow 1.90$ \\
\hline 793.56342 & $\operatorname{PE}(20: 1(11 Z) / 20: 4(8 Z, 11 Z, 14 Z, 17 Z))$ & $* 60664$ & + & $\downarrow 3.34$ \\
\hline 437.29129 & PE(P-16:0e/0:0) & HMDB0011152 & + & $\downarrow 1.21$ \\
\hline 193.09526 & Phenylacetylglycine & $\wedge 540$ & + & $\downarrow 6.82$ \\
\hline 164.04758 & Phenylpyruvic acid & $\wedge 1389$ & + & $\downarrow 1.47$ \\
\hline 390.35369 & Phosphoribosyl-pyrophosphate & $\wedge 264$ & + & $\downarrow 1.08$ \\
\hline 225.94431 & Porphobilinogen & $\wedge 1330$ & + & $\downarrow 2.71$ \\
\hline 143.09489 & Proline betaine & HMDB0004827 & + & $\downarrow 2.05$ \\
\hline 218.12684 & Propionylcarnitine & $\wedge 884$ & + & $\downarrow 1.26$ \\
\hline 383.10805 & Succinyladenosine & HMDB0000912 & + & $\downarrow 1.04$ \\
\hline 241.91824 & Thymidine & $\wedge 1230$ & + & $\downarrow 2.05$ \\
\hline 112.02762 & Uracil & HMDB0000300 & + & $\downarrow 1.37$ \\
\hline 281.04194 & 1-Methyladenosine & $\wedge 105$ & - & $\uparrow 1.24$ \\
\hline 216.03884 & 2-C-Methyl-D-erythritol 4-phosphate & $* 64013$ & - & $\uparrow 2.38$ \\
\hline 133.03601 & L-Aspartic acid & $\wedge 462$ & - & $\uparrow 1.89$ \\
\hline 131.06803 & Creatine & $\wedge 357$ & - & $\uparrow 1.44$ \\
\hline 260.02867 & Glucose-6-phosphate & HMDB0001401 & - & $\uparrow 3.90$ \\
\hline 169.04910 & Norepinephrine & $\wedge 318$ & - & $\uparrow 2.04$ \\
\hline 246.04947 & Phosphatidylglycerol & $* 186$ & - & $\uparrow 1.82$ \\
\hline 226.08094 & Porphobilinogen & $\wedge 1330$ & - & $\uparrow 1.82$ \\
\hline 168.02694 & Uric acid & $\wedge 753$ & - & $\uparrow 1.80$ \\
\hline 233.90871 & 5-Methoxytryptophan & $\wedge 2613$ & - & $\downarrow 1.56$ \\
\hline 283.09054 & 8-Hydroxy-deoxyguanosine & HMDB0003333 & - & $\downarrow 1.82$ \\
\hline 249.96666 & $\gamma$-Glutamylcysteine & $\wedge 427$ & - & $\downarrow 1.99$ \\
\hline 222.01841 & L-Cystathionine & $\wedge 1829$ & - & $\downarrow 1.48$ \\
\hline 204.02472 & L-Tryptophan & $\wedge 1830$ & - & $\downarrow 1.25$ \\
\hline 189.06253 & N-Acetyl-L-glutamic acid & $\wedge 1832$ & - & $\downarrow 1.78$ \\
\hline 218.05446 & N-Acetylserotonin & $\wedge 313$ & - & $\downarrow 1.50$ \\
\hline 347.06214 & Adenosine monophosphate (AMP) & HMDB0000045 & - & $\downarrow 1.54$ \\
\hline 317.95390 & Coenzyme Q2 & $\wedge 379$ & - & $\downarrow 1.45$ \\
\hline 148.07208 & Mevalonic acid & $\wedge 1338$ & - & $\downarrow 1.82$ \\
\hline 167.02385 & Quinolinic acid & $\wedge 1262$ & - & $\downarrow 1.53$ \\
\hline
\end{tabular}

Putative metabolites were annotated by cross-referencing the online databases including Human Metabolome Database (HMDB), Metlin $(*)$ and mzCloud $(\wedge)$. Symbol: $(\uparrow)$ increased; $(\downarrow)$ decreased. Abbreviation: ESI (electrospray ionization); FC (fold change); $\mathrm{m} / \mathrm{w}$ (molecular weight). The list was sorted according to ionization mode, up- or downregulation, followed by alphabetical order 
projections were not over-fit by OPLS-DA; while the permutation test for $\mathrm{R}^{2} \mathrm{Y}$ between 200TRF and control groups was insignificant (Table 1). For the former two group comparisons, $\mathrm{Q}^{2}$ and $\mathrm{R}^{2} \mathrm{Y}$ values based on crossvalidation were high $(>70 \%)$, indicating that the projections had good predictability (Eritja et al. 2017).

A total of 190 metabolites were differentially expressed between MI rats and control groups with 84 of them were annotated by cross-referencing to the online databases (Table 2). On the other hand, a total of 85 metabolites were differentially expressed between 200TRF+MI and MI groups with 37 of them were annotated. Since OPLS-DA did not produce a distinct separation between 200TRF and control groups, the number of DEMs, as well as metabolites annotation procedures, were not performed.

Table 3 shows the list of annotated DEMs in between MI and control groups. Out of 84 metabolites, 64 were detected in positive ion mode while another 20 metabolites were found in negative ion mode.

Table 4 lists the annotated DEMs in between 200TRF+MI and MI groups. From 37 annotated metabolites, 30 and 7 metabolites were detected in positive and negative modes, respectively.

Pathway analysis based on annotated DEMs showed that MI and TRF supplementation affected several metabolic pathways in the rats' myocardium. Comparing between MI and control as well as 200TRF+MI and MI groups, pathways that are relevant to both group comparisons include cysteine and methionine metabolism, nicotinate and nicotinamide metabolism, pentose phosphate pathway, as well as starch and sucrose metabolism (Figure 4).

Since MI induced by ISO administration produced marked myocyte loss as well as increased fibrosis within the subendocardium of rat's left ventricular free wall (Brooks \& Conrad 2009), this part of the heart was selected for metabolomic assessment in the current study. Metabolomic analysis utilizing UHPLC-Orbitrap MS followed by multivariate analysis using the OPLS-DA technique could differentiate and identify metabolic changes in the myocardial tissue of control, MI and 200TRF+MI rats. Interestingly, non-supplemented MI resulted in alterations of different sets of biochemical processes than TRF-supplemented MI rats. This indicates that TRF might protect against MI from biochemical aspects dissimilar than during the disease development itself. Nevertheless, four metabolic pathways were observed to be affected in both MI vs control and 200TRF+MI vs MI group comparisons.

\section{Cysteine and Methionine Metabolism}

Methionine is an essential amino acid for humans with a recommended daily intake of $15 \mathrm{mg} / \mathrm{kg} /$ day (Kurpad et al. 2003). Metabolism of methionine would produce intermediates such as S-adenosylmethionine (SAM), S-adenosylhomocysteine (SAH), homocysteine and L-cystathionine (Poloni et al. 2015). The enzyme cystathionine- $\beta$-synthase (CBS) is responsible for the synthesis of L-cystathionine from homocysteine (Koutmos et al. 2010). Furthermore, trans-sulfuration process of L-cystathionine by cystathionine- $\gamma$-lyase will transform it into cysteine, an initial substrate in glutathione (GSH) synthesis (Kabil et al. 2011).

Deficiency of CBS causes hyperhomocysteinemia, which is an established risk factor for cardiovascular disease that includes pre-mature MI (Ukachukwu et al. 2012). An earlier study reported that CBS could be allosterically activated by SAM which also stabilized the enzyme and improved cell viability under oxidative stress condition (Prudova et al. 2006). In the current study, since the reduction of L-cystathionine as well as SAM occurred in the myocardial tissue of MI rats by 1.48 and 1.20 times compared to control, respectively, it gave an impression that destabilization of CBS might have occurred in MI. Using metabolomics approach in rat MI model induced by coronary artery ligation, Prudova et al. (2006) reported that myocardial SAM concentration decreased gradually in a time-dependent manner and downregulated significantly at day 10 post-MI (Nam et al. 2017), which was consistent with our findings.

TRF might protect myocardial tissue against MI by reversing these changes. In the current study, MI rats receiving TRF supplementation for 12 weeks had a significant elevation of L-cystathionine as well as SAM by 1.97 and 1.95 times compared to MI group, respectively. These changes reflected that TRF might be able to activate CBS by increasing the expression of SAM, its allosteric activator. Subsequently, this would enhance conversion of homocysteine to L-cystathionine as well as drive glutathione production via cysteine synthesis. Indeed, the relation between vitamin E and SAM had been demonstrated in earlier work. When mouse primary hepatocyte was exposed to ethanol, the resulting increased oxidative stress led to a marked decrease of SAM/SAH ratio by $53 \%$ while treatment with vitamin E significantly prevented this alteration (Gyamfi \& Wan 2006).

Therefore, inhibition of cysteine and methionine metabolism in MI might have a direct impact on the antioxidative system via GSH synthesis due to decreased SAM production that was successfully reversed by TRF supplementation.

\section{Nicotinate and Nicotinamide Metabolism}

MI is strongly related to increased production of reactive oxygen species including hydrogen peroxide $\left(\mathrm{H}_{2} \mathrm{O}_{2}\right)$ that leads to oxidative stress (Bae et al. 2016). The process of neutralizing $\mathrm{H}_{2} \mathrm{O}_{2}$ into water molecule requires concerted efforts by glutathione and co-factor nicotinamide adenine dinucleotide phosphate (NADP) (Arai et al. 2017; Berkholz et al. 2008). NADP is generated from nicotinate and nicotinamide metabolism. In this biochemical process, nicotinic acid and nicotinamide would be converted to nicotinamide adenine dinucleotide (NAD) via the PreissHandler pathway and salvage pathway, respectively (Singhal \& Cheng 2019). This would be followed by 
TABLE 4. List of annotated DEMs in between ISO-induced MI rats receiving $200 \mathrm{mg} / \mathrm{kg} /$ day TRF and MI group

\begin{tabular}{|c|c|c|c|c|}
\hline \multicolumn{5}{|c|}{ 200TRF+MI vs MI } \\
\hline $\mathrm{m} / \mathrm{w}$ & Putative Metabolites & Identifiers & ESI & $\mathrm{FC}$ \\
\hline 260.13719 & $\gamma$-Glutamyl-L-isoleucine & HMDB0011170 & + & $\uparrow 1.65$ \\
\hline 155.03487 & L-Histidine & $\wedge 473$ & + & $\uparrow 1.59$ \\
\hline 399.37128 & S-Adenosylmethionine & $\wedge 896$ & + & $\uparrow 1.95$ \\
\hline 267.09692 & Adenosine & HMDB0000050 & + & $\uparrow 1.53$ \\
\hline 511.49656 & $\operatorname{Cer}(\mathrm{d} 18: 0 / 14: 0)$ & HMDB0011759 & + & $\uparrow 1.97$ \\
\hline 539.52779 & $\operatorname{Cer}(\mathrm{d} 18: 0 / 16: 0)$ & HMDB0011760 & + & $\uparrow 2.96$ \\
\hline 543.33311 & Lysophosphatidylcholine(20:4) & HMDB0010395 & + & $\uparrow 7.90$ \\
\hline 437.29129 & $\mathrm{PE}(\mathrm{P}-16: 0 \mathrm{e} / 0: 0)$ & HMDB0011152 & + & $\uparrow 11.28$ \\
\hline 390.35369 & Phosphoribosyl-pyrophosphate & $\wedge 264$ & + & $\uparrow 1.91$ \\
\hline 218.12684 & Propionylcarnitine & $\wedge 884$ & + & $\uparrow 1.41$ \\
\hline 393.86701 & 2-(14,15-Epoxyeicosatrienoyl) glycerol & $\wedge 4758$ & + & $\downarrow 2.70$ \\
\hline 214.06244 & 2-Deoxyribose 5-phosphate & $\wedge 1511$ & + & $\downarrow 3.17$ \\
\hline 145.11044 & 3-Dehydroxycarnitine & HMDB0006831 & + & $\downarrow 3.38$ \\
\hline 219.99107 & L-5-Hydroxytryptophan & $\wedge 1540$ & + & $\downarrow 1.41$ \\
\hline 240.13492 & L-Anserine & $\wedge 1308$ & + & $\downarrow 1.53$ \\
\hline 158.06931 & L-Dihydroorotic acid & $\wedge 1543$ & + & $\downarrow 2.56$ \\
\hline 309.10605 & N-Acetylneuraminic acid & HMDB0000230 & + & $\downarrow 1.56$ \\
\hline 217.97662 & N-Acetylserotonin & $\wedge 313$ & + & $\downarrow 1.48$ \\
\hline 206.04355 & (R)-Lipoic acid & HMDB0001451 & + & $\downarrow 1.30$ \\
\hline 260.02988 & Glucose-6-phosphate & HMDB0001401 & + & $\downarrow 2.85$ \\
\hline 111.08001 & Histamine & HMDB0000870 & + & $\downarrow 1.50$ \\
\hline 109.06441 & Hypotaurine & $\wedge 440$ & + & $\downarrow 1.62$ \\
\hline 228.14756 & Leucylproline & HMDB0011175 & + & $\downarrow 2.74$ \\
\hline 121.91751 & Nicotinamide (niacinamide) & $\wedge 517$ & + & $\downarrow 6.89$ \\
\hline 122.58708 & Nicotinic acid & $\wedge 519$ & + & $\downarrow 3.07$ \\
\hline 506.26443 & Phosphatidylglycerol & $* 80008$ & + & $\downarrow 4.44$ \\
\hline 143.09489 & Proline betaine & HMDB0004827 & + & $\downarrow 2.12$ \\
\hline 561.79007 & Protoporphyrin IX & $\wedge 1354$ & + & $\downarrow 3.17$ \\
\hline 299.28268 & Sphingosine & HMDB0000252 & + & $\downarrow 1.90$ \\
\hline 427.36636 & Stearoylcarnitine & HMDB00848 & + & $\downarrow 2.05$ \\
\hline 249.96666 & $\gamma$-Glutamylcysteine & $\wedge 427$ & - & $\uparrow 1.34$ \\
\hline 222.01841 & L-Cystathionine & $\wedge 1829$ & - & $\uparrow 1.97$ \\
\hline 189.06253 & N-Acetyl-L-glutamic acid & $\wedge 1832$ & - & $\uparrow 2.27$ \\
\hline 347.06214 & Adenosine monophosphate (AMP) & HMDB0000045 & - & $\uparrow 1.48$ \\
\hline 244.06850 & Uridine & HMDB0000296 & - & $\uparrow 1.61$ \\
\hline 131.06803 & Creatine & $\wedge 357$ & - & $\downarrow 1.42$ \\
\hline 226.08094 & Porphobilinogen & $\wedge 1330$ & - & $\downarrow 1.70$ \\
\hline
\end{tabular}

Putative metabolites were annotated by cross-referencing the online databases including Human Metabolome Database $(\mathrm{HMDB})$, Metlin $(*)$ and mzCloud $(\wedge)$. Symbol: $(\uparrow)$ increased; $(\downarrow)$ decreased. Abbreviation: ESI (electrospray ionization); FC (fold change); $\mathrm{m} / \mathrm{w}$ (molecular weight). The list was sorted according to ionization mode, up- or downregulation, followed by alphabetical order 
ESI (+)

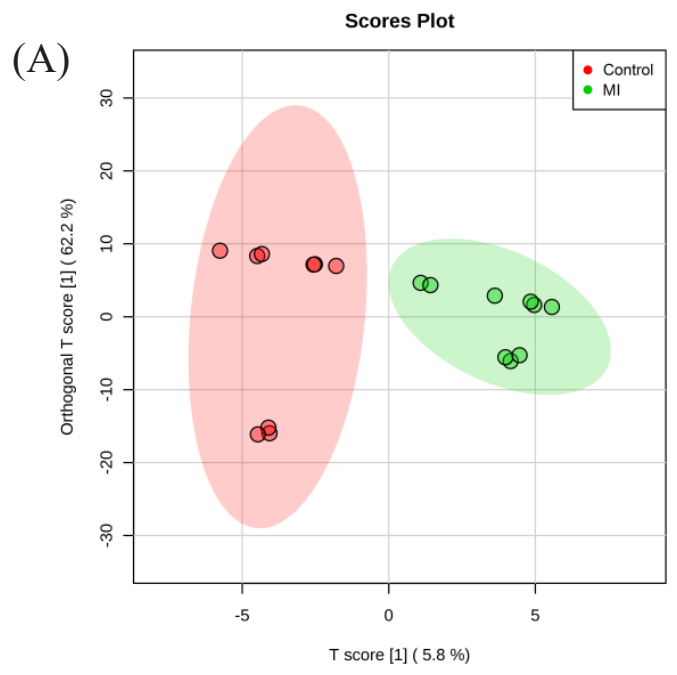

(C)

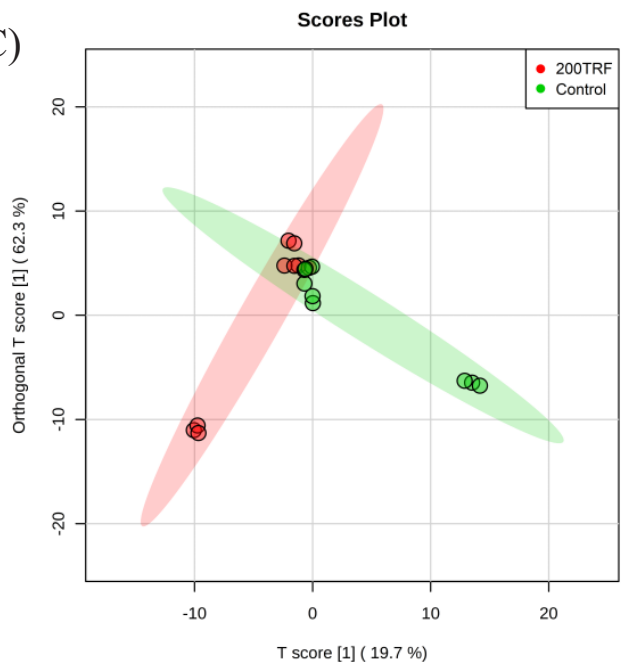

(E)

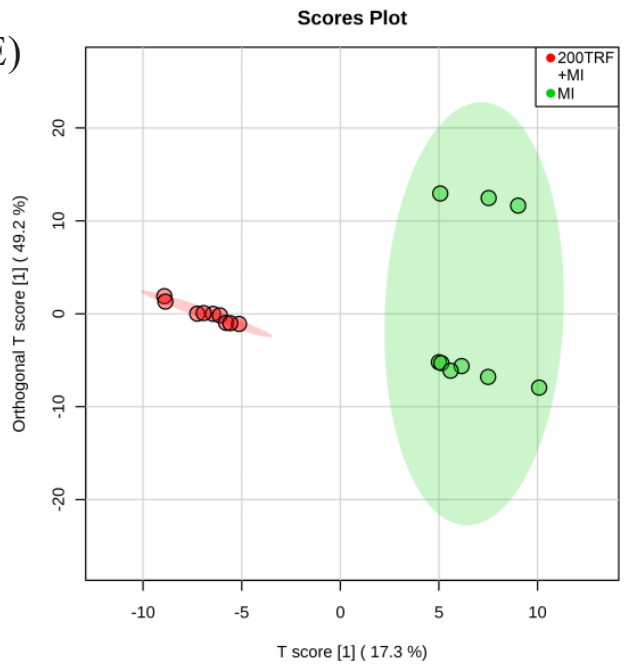

ESI (-)
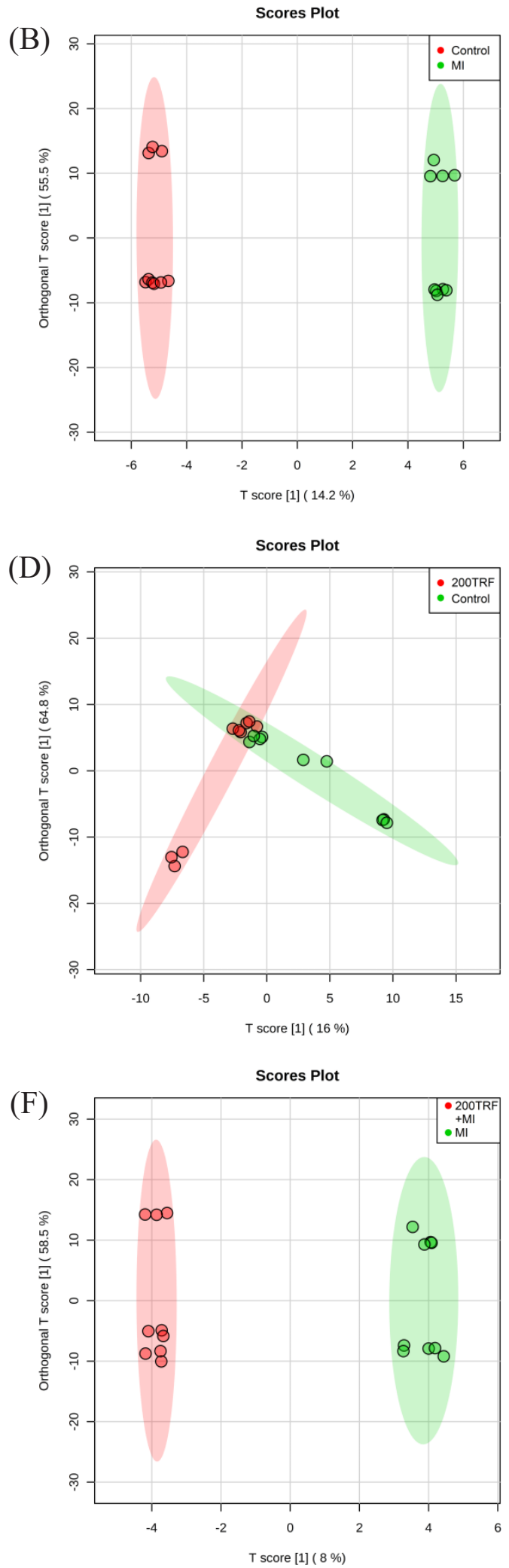

FIGURE 3. Score plot for Orthogonal Projections to Latent Structures Discriminant Analysis (OPLS-DA). (A-B) ESI (+) and (-) for MI vs control; (C-D) ESI (+) and (-) for 200TRF vs control; (E-F) ESI (+) and (-) for 200TRF+MI vs MI. Each group consisted of three biological replicates with three technical replicates for every biological sample. Each point represents one replicate 
(A)

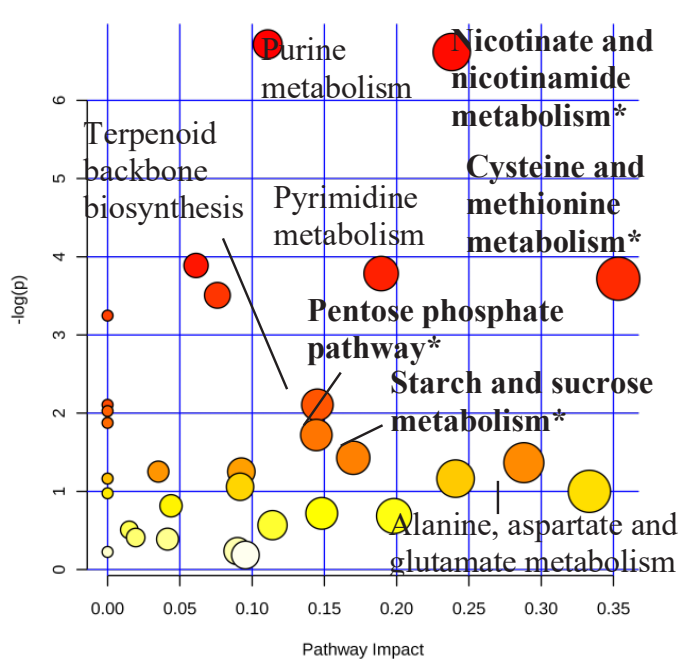

(B)

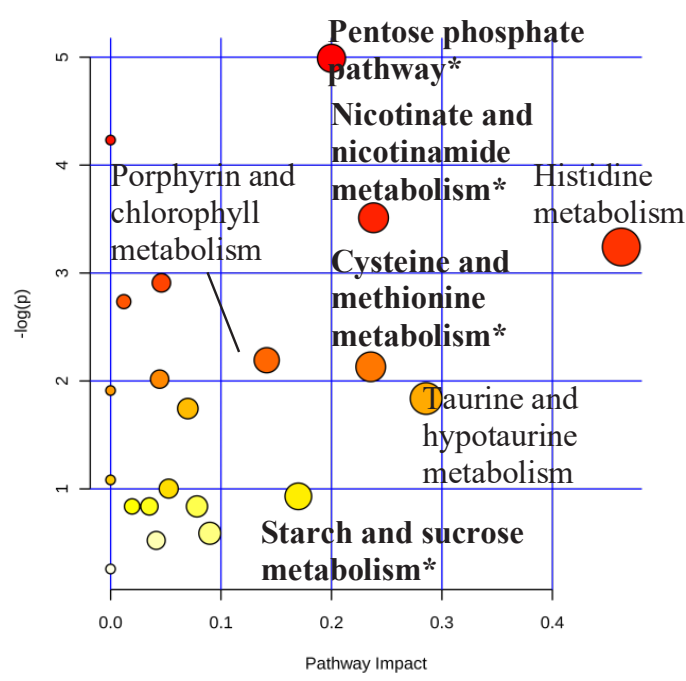

FIGURE 4. Overview of pathway analysis showed altered metabolic pathways for (A) MI vs control and (B) $200 \mathrm{TRF}+\mathrm{MI}$ vs MI. Affected pathways present in both group comparisons were marked with $\left(^{*}\right)$ and written in bold letters

phosphorylation of NAD to NADP by NAD kinase (Love et al. 2015).

In the current study, reduction of nicotinic acid and nicotinamide (or niacinamide) occurred by 1.26 and 1.31 times, respectively, in MI compared to control. Incidentally, $\gamma$-glutamylcysteine molecule, an intermediate in GSH synthesis (Wu et al. 2004), was also found to be decreased by 1.99 times indicating a disturbance in new GSH molecule production. From these findings, we could infer that myocardium might rely on pre-existing GSH in combating oxidative stress to form oxidized glutathione (GSSG), thus lowering the GSH itself. In fact, previous study reported that myocardial GSH concentration was reduced by approximately $40 \%$ during MI due to conversion from GSH to GSSG (Li et al. 2009). Reduced nicotinic acid and nicotinamide in heart homogenate of MI rats in the current study could be explained as a physiological response to limit oxidative damage where these molecules might be channeled into NAD and NADP syntheses to keep the pre-existing glutathione in its reduced state.

Supplementation of MI rats with $200 \mathrm{mg} / \mathrm{kg}$ /day TRF for 12 weeks resulted in further reduction of nicotinic acid and nicotinamide by 3.07 and 6.89 times compared to MI rats, respectively. However, they were accompanied by 1.34 times increased of $\gamma$-glutamylcysteine expression which reflected that TRF might help in the generation of new GSH molecules. Report from the previous study could support this inference. By using rat model, MI group receiving vitamin $\mathrm{E}$ supplementation at the dose of 1,500 $\mathrm{U} / \mathrm{kg} /$ day for a short duration of 16 days had significantly increased myocardial GSH concentration from $37.4 \pm 3.4$ $\mathrm{nmol} / \mathrm{g}$ to $65.3 \pm 5.0 \mathrm{nmol} / \mathrm{g}(p<0.05)$ as compared to nonsupplemented MI rats (Hill et al. 2005).

Pentose Phosphate Pathway

Myocardial tissue damage during MI is contributed by apoptosis and necrosis that lead to nuclear and mitochondrial deoxyribonucleic acid (DNA) release as well as increased purine metabolism (Casey et al. 2007; Fauconnier et al. 2011). This process had been substantiated in the previous study whereby plasma DNA concentration derived from both nucleus and mitochondria elevated significantly in acute MI patients compared to control group (Wang et al. 2015). As a result, serum metabolites involving purine degradation were also increased significantly (Al-Shamiri et al. 2009). Since there is a flux of damaged DNA and metabolites of purine degradation into the bloodstream from the infarcted heart, their concentrations naturally would decrease in the tissue itself. Certainly, metabolic profile in the current study found that myocardial adenosine and adenosine monophosphate (AMP) were decreased by 2.00 and 1.54 times, respectively, in MI rats compared to control.

Pentose phosphate pathway is closely related to purine metabolism. The molecule phosphoribosyl-pyrophosphate (PRPP), which represented the pathway, is vital in purine salvage process (McCarthy et al. 2018). Availability of PRPP closely affected the rate of adenosine salvage in rat cardiomyocytes (Dow et al. 1987). Adenosine kinase could transform adenosine directly to AMP. Additionally, adenosine could be first converted to adenine before adenine phosphoribosyltransferase enzyme catalyzed an AMP-producing reaction that requires ribose phosphate moiety from PRPP (Buckoreelall et al. 2011; Frenguelli 2019). Hence, in the current study, reduction of adenosine and AMP accompanied by reduced PRPP by 1.08 times indicated that there was a reduced purine salvage process due to impaired pentose phosphate pathway in MI.

Conversely, MI rats receiving TRF supplementation had a significant reversal of these changes than untreated MI group with an elevation of 1.53, 1.48 and 1.91 times each for adenosine, AMP and PRPP. These findings suggested that the cardioprotective mechanism of TRF might be related to the activation of the purine salvage 




FIGURE 5. Overview of the altered metabolic profile and biochemical pathways in MI and the effects of TRF supplementation. Pathways involved are (1) Cysteine and methionine metabolism, (2) Nicotinate and nicotinamide metabolism, (3) Pentose phosphate pathway, and (4) Starch and sucrose metabolism. Symbol: Red arrow (metabolite changes in MI vs control), green arrow (metabolite changes in 200TRF+MI vs MI). Purine salvage pathway was marked with $\left({ }^{*}\right)$. Abbreviation: AMP (adenosine monophosphate), GSH (reduced glutathione), GSSG (oxidized glutathione), $\mathrm{H} 2 \mathrm{O}$ (water), $\mathrm{H} 2 \mathrm{O} 2$ (hydrogen peroxide), $\mathrm{NADH}$ (nicotinamide adenine dinucleotide), NADP+/NADPH (nicotinamide adenine dinucleotide phosphate), O2•- (superoxide), PRPP (phosphoribosyl-pyrophosphate), SAH (S-adenosylhomocysteine), SAM (S-adenosylmethionine)

pathway in order to regenerate new substrates for DNA synthesis. Salvage pathway requires lower energy as compared to de novo purine synthesis (Moffatt \& Ashihara 2002). Cardiomyocytes had been reportedly suffered from reduced energy production in a hypoxic environment (Qiu et al. 2018). As such, this energy-saving process is very crucial in MI.

\section{Starch and Sucrose Metabolism}

During prolonged hypoxia, there is a sudden decrease in oxygen supply resulting in cardiac ischemia. The lack of oxygen causes mitochondria to function sub-optimally and disrupts the tricarboxylic acid (TCA) cycle, long-chain fatty acids $\beta$-oxidation and electron transfer through the electron transport chain resulting in rapid shortages of ATP generation (Mitra et al. 2015; Whitmer et al. 1978). This interference leads to conversion of aerobic to anaerobic glycolysis where the rate of glucose oxidation to lactate increases (Gandhi \& Akholkar 2015).

Starch and sucrose metabolism represented by glucose-6-phosphate is another important metabolic pathway that was altered in both MI vs control and 200TRF+MI vs MI group comparisons. The metabolite is a product of the initial reaction of anaerobic glycolysis catalyzed by glucokinase (Lenzen 2014). In the current study, glucose-6-phosphate was increased by 3.90 times in MI as compared to control rats which indirectly suggested that blood glucose concentration might be elevated as well. A cross-sectional study in human subjects found that the degree of MI severity was closely related to higher blood glucose readings at the time of hospital admission regardless of whether the patients had prior diabetes mellitus or not. MI patients with moderately high (7.8-11.0 mmol/L) and severely high $(\geq 11.1 \mathrm{mmol} / \mathrm{L})$ blood glucose had higher mortality risk than their euglycemic counterparts (Zhao et al. 2017). Furthermore, a study by Ali et al. (2016) utilizing gas chromatography-mass spectrometry and proton nuclear magnetic resonance techniques found that serum $\alpha$ - and $\beta$-glucose levels in acute MI patients were significantly raised, with $p$-value $<0.0001$ for each observation.

On the contrary, myocardial glucose-6-phosphate was significantly reduced by 2.85 times in $200 \mathrm{TRF}+\mathrm{MI}$ compared to MI rats. From this finding, we could deduce that TRF supplementation might revert the anaerobic glycolysis back to aerobic process as well as improve overall glucose utilization within the myocardial tissue. Earlier study demonstrated that supplementation of $\alpha$ - and $\gamma$-tocopherol mixture significantly increased transcription of genes related to glycolysis (aldolase, enolase, and glucose phosphate isomerase), TCA cycle (isocitrate, succinate, and malate dehydrogenases) and ATP synthesis (mitochondrial $\mathrm{F}_{0}$, and $\mathrm{F}_{1}$ complexes of ATP synthase) in aged mouse brain (Park et al. 2008). Perhaps, a similar 
mechanism might have occurred in the cardiac tissue of 200TRF+MI rats whereby TRF might improve mitochondrial functions which directly enhanced aerobic glycolysis, TCA cycle as well as energy production in the form of ATP synthesis.

The roles of these metabolic pathways on the pathogenesis of MI and cardioprotective mechanisms of TRF worth further confirmatory studies to provide new insights for prevention and treatment of MI. Figure 5 summarizes the metabolic profile and biochemical pathway changes that were involved in MI and the effects of TRF supplementation.

\section{CONCLUSION}

Supplementation of TRF increased serum $\alpha$-tocopherol but not serum tocotrienol possibly due to the differences in the bioavailability of vitamin E's vitamers. In ISOinduced MI rats, TRF reversed the changes of metabolic pathways involving cysteine and methionine metabolism, nicotinate and nicotinamide metabolism, pentose phosphate pathway as well as starch and sucrose metabolism that were altered by MI. Ultimately, the changes brought by TRF might positively affect myocardial antioxidative system via new GSH production, activate adenosine salvage pathway possibly for DNA synthesis, and enhance glucose utilization through aerobic glycolysis.

\section{ACKNOWLEDGEMENTS}

This research was funded by Universiti Kebangsaan Malaysia, grant number AP-2014-024 and UKM Medical Centre, grant number FF-2018-062. We would also like to thank postgraduate students, technical staffs and all academicians from the Department of Biochemistry, Universiti Kebangsaan Malaysia, for their help and support.

\section{REFERENCES}

Al-Shamiri, S.A., Hasan, N.A., Frankul, W.M. \& Al-Hamdi, A.T. 2009. Purines and oxypurines in myocardial ischemia. Saudi Medical Journal 30(2): 257-266.

Ali, S.E., Farag, M.A., Holvoet, P., Hanafi, R.S. \& Gad, M.Z. 2016. A comparative metabolomics approach reveals early biomarkers for metabolic response to acute myocardial infarction. Scientific Reports 6: 36359.

Arai, K., Tashiro, A., Osaka, Y. \& Iwaoka, M. 2017. Glutathione peroxidase-like activity of amino-substituted water-soluble cyclic selenides: A shift of the major catalytic cycle in methanol. Molecules 22(3): 354.

Atia, A. \& Abdullah, A. 2014. Tocotrienols: The other half of natural vitamin E. Research Journal of Pharmaceutical, Biological and Chemical Sciences 5(2): 533-543.

Bae, S., Park, M., Kang, C., Dilmen, S., Kang, T.H., Kang, D.G., Ke, Q., Lee, S.U., Lee, D. \& Kang, P.M. 2016. Hydrogen peroxide-responsive nanoparticle reduces myocardial ischemia/reperfusion injury. Journal of the American Heart Association 5(11): e003697.
Bardhan, J., Chatterjee, A., Das, S., Bandyopadhyay, S.K., Chakraborty, R. \& Raychaudhuri, U. 2015. Evaluation of cardioprotective effect of tocotrienol rich fraction from rice bran oil. International Journal of Pharmaceutical Sciences Review and Research 30(1): 143-149.

Berkholz, D.S., Faber, H.R., Savvides, S.N. \& Karplus, P.A. 2008. Catalytic cycle of human glutathione reductase near $1 \AA$ Å resolution. Journal of Molecular Biology 382(2): 371384.

Biaggiono, I. \& Robertson, D. 2014. Adrenoceptor agonists \& sympathomimetic drugs. In Basic \& Clinical Pharmacology, edited by Katzung, B.G. \& Trevor, A.J. 13th ed. New York: McGraw-Hill Education. pp. 133-151.

Brooks, W.W. \& Conrad, C.H. 2009. Isoproterenol-induced myocardial injury and diastolic dysfunction in mice: Structural and functional correlates. Comparative Medicine 59(4): 339-343.

Buckoreelall, K., Wilson, L. \& Parker, W.B. 2011. Identification and characterization of two adenosine phosphorylase activities in Mycobacterium smegmatis. Journal of Bacteriology 193(20): 5668-5674.

Casey, T.M., Arthur, P.G. \& Bogoyevitch, M.A. 2007. Necrotic death without mitochondrial dysfunction-delayed death of cardiac myocytes following oxidative stress. Biochimica et Biophysica Acta 1773(3): 342-351.

Che-Muzaini, C.M. \& Norsa'adah, B. 2017. Complications of acute coronary syndrome in young patients. Iranian Journal of Public Health 46(1): 139-140.

Chong, J., Soufan, O., Li, C., Caraus, I., Li, S., Bourque, G., Wishart, D.S. \& Xia, J. 2018. MetaboAnalyst 4.0: Towards more transparent and integrative metabolomics analysis. Nucleic Acids Research 46(W1): W486-W494.

Clark-Matott, J., Saleem, A., Dai, Y., Shurubor, Y., Ma, X., Safdar, A., Beal, M.F., Tarnopolsky, M. \& Simon, D.K. 2015. Metabolomic analysis of exercise effects in the POLG mitochondrial DNA mutator mouse brain. Neurobiology of Aging 36(11): 2972-2983.

Das, M., Das, S., Wang, P., Powell, S.R. \& Das, D.K. 2008. Caveolin and proteasome in tocotrienol mediated myocardial protection. Cellular Physiology and Biochemistry 22(1-4): 287-294.

Dieplinger, H. \& Dieplinger, B. 2015. Afamin-A pleiotropic glycoprotein involved in various disease states. Clinica Chimica Acta 446: 105-110.

Dow, J.W., Bowditch, J., Nigdikar, S.V. \& Brown, A.K. 1987. Salvage mechanisms for regeneration of adenosine triphosphate in rat cardiac myocytes. Cardiovascular Research 21(3): 188-196.

Durani, L.W., Hamezah, H.S., Ibrahim, N.F., Yanagisawa, D., Makpol, S., Damanhuri, H.A. \& Tooyama, I. 2017. Age-related changes in the metabolic profiles of rat hippocampus, medial prefrontal cortex and striatum. Biochemical and Biophysical Research Communications 493(3): 1356-1363.

Eritja, N., Jové, M., Eldevik Fasmer, K., Gatius, S., PorteroOtin, M., Trovik, J., Krakstad, C., Sol, J., Pamplona, R., Haldorsen, I.S. \& Matias-Guiu, X. 2017. Tumourmicroenvironmental blood flow determines a metabolomic signature identifying lysophospholipids and resolvin D as biomarkers in endometrial cancer patients. Oncotarget 8(65): 109018-109026.

Fairus, S., Nor, R.M., Cheng, H.M. \& Sundram, K. 2012. Alpha-tocotrienol is the most abundant tocotrienol isomer 
circulated in plasma and lipoproteins after postprandial tocotrienol-rich vitamin E supplementation. Nutrition Journal 11: 5.

Fairus, S., Nor, R.M., Cheng, H.M. \& Sundram, K. 2006. Postprandial metabolic fate of tocotrienol-rich vitamin E differs significantly from that of $\alpha$-tocopherol. The American Journal of Clinical Nutrition 84(4): 835-842.

Fauconnier, J., Meli, A.C., Thireau, J., Roberge, S., Shan, J., Sassi, Y., Reiken, S.R., Rauzier, J.M., Marchand, A., Chauvier, D., Cassan, C., Crozier, C., Bideaux, P., Lompre, A.M., Jacotot, E., Marks, A.R. \& Lacampagne, A. 2011. Ryanodine receptor leak mediated by caspase-8 activation leads to left ventricular injury after myocardial ischemiareperfusion. Proceedings of the National Academy of Sciences of the United States of America 108(32): 1325813263.

Finegold, J.A., Asaria, P. \& Francis, D.P. 2013. Mortality from ischaemic heart disease by country, region, and age: Statistics from World Health Organisation and United Nations. International Journal of Cardiology 168(2): 934945.

Frenguelli, B.G. 2019. The purine salvage pathway and the restoration of cerebral ATP: Implications for brain slice physiology and brain injury. Neurochemical Research 44(3): 661-675.

Gandhi, A.A. \& Akholkar, P.J. 2015. Metabolic acidosis in acute myocardial infarction. International Journal of Advances in Medicine 2(3): 260-263.

Gyamfi, M.A. \& Wan, Y.J.Y. 2006. The effect of ethanol, ethanol metabolizing enzyme inhibitors, and vitamin E on regulating glutathione, glutathione S-transferase, and S-adenosylmethionine in mouse primary hepatocyte. Hepatology Research 35(1): 53-61.

Hill, M.F., Palace, V.P., Kaur, K., Kumar, D., Khaper, N. \& Singal, P.K. 2005. Reduction in oxidative stress and modulation of heart failure subsequent to myocardial infarction in rats. Experimental and Clinical Cardiology 10(3): 146-153.

Horgan, R.P. \& Kenny, L.C. 2011. 'Omic' technologies: Genomics, transcriptomics, proteomics and metabolomics. The Obstetrician \& Gynaecologist 13: 189-195.

Huang, G., Liu, X., Jiao, L., Xu, C., Zhang, Z., Wang, L., Li, Y., Yang, C., Zhang, W. \& Sun, Y. 2014. Metabolomic evaluation of the response to endocrine therapy in patients with prostate cancer. European Journal of Pharmacology 729: 132-137.

Institute of Medicine. 2010. Promoting Cardiovascular Health in the Developing World: A Critical Challenge to Achieve Global Health. Washington: The National Academies Press.

Jaafar, F., Abdullah, A. \& Makpol, S. 2018. Cellular uptake and bioavailability of tocotrienol-rich fraction in SIRT1inhibited human diploid fibroblasts. Scientific Reports 8(1): 10471.

Jung, Y., Lee, J., Kwon, J., Lee, K.S., Ryu, D.H. \& Hwang, G.S. 2010. Discrimination of the geographical origin of beef by ${ }^{1} \mathrm{H}$ NMR-based metabolomics. Journal of Agricultural and Food Chemistry 58(19): 10458-10466.

Kabil, O., Vitvitsky, V., Xie, P. \& Banerjee, R. 2011. The quantitative significance of the transsulfuration enzymes for $\mathrm{H}_{2} \mathrm{~S}$ production in murine tissues. Antioxidants \& Redox Signaling 15(2): 363-372.

Kannappan, R., Gupta, S.C., Kim, J.H. \& Aggarwal, B.B. 2012. Tocotrienols fight cancer by targeting multiple cell signaling pathways. Genes \& Nutrition 7(1): 43-52.
Khor, S.C., Razak, A.M., Wan Ngah, W.Z., Mohd Yusof, Y.A., Abdul Karim, N. \& Makpol, S. 2016. The tocotrienol-rich fraction is superior to tocopherol in promoting myogenic differentiation in the prevention of replicative senescence of myoblasts. PLoS ONE 11(2): e0149265.

Koutmos, M., Kabil, O., Smith, J.L. \& Banerjee, R. 2010. Structural basis for substrate activation and regulation by cystathionine beta-synthase (CBS) domains in cystathionine $\beta$-synthase. Proceedings of the National Academy of Sciences 107(49): 20958-20963.

Kurpad, A.V., Vasudevan, J., Gnanou, J., Regan, M.M., Varalakshmi, S., Raj, T. \& Young, V.R. 2003. Daily methionine requirements of healthy Indian men, measured by a 24-h indicator amino acid oxidation and balance technique. The American Journal of Clinical Nutrition 77(5): 1198-1205.

Lee, K.Y., Wan Ahmad, W.A., Low, E.V., Liau, S.Y., Anchah, L., Hamzah, S., Liew, H.B., Mohd Ali, R.B., Ismail, O., Ong, T.K., Said, M.A. \& Dahlui, M. 2017. Comparison of the treatment practice and hospitalization cost of percutaneous coronary intervention between a teaching hospital and a general hospital in Malaysia: A cross sectional study. PLoS ONE 12(9): 0184410.

Lenzen, S. 2014. A fresh view of glycolysis and glucokinase regulation: History and current status. The Journal of Biological Chemistry 289(18): 12189-12194.

Li, S., Zheng, M.Q. \& Rozanski, G.J. 2009. Glutathione homeostasis in ventricular myocytes from rat hearts with chronic myocardial infarction. Experimental Physiology 94(7): 815-824.

Liu, Y., Jia, H., Chang, X., Ding, G., Zhang, H. \& Zou, Z.M. 2013. The metabolic disturbances of isoproterenol induced myocardial infarction in rats based on a tissue targeted metabonomics. Molecular BioSystems 9(11): 2823-2834.

Love, N.R., Pollak, N., Dölle, C., Niere, M., Chen, Y., Oliveri, P., Amaya, E., Patel, S. \& Ziegler, M. 2015. NAD kinase controls animal NADP biosynthesis and is modulated via evolutionarily divergent calmodulin-dependent mechanisms. Proceedings of the National Academy of Sciences 112(5): 1386-1391.

Madhesh, M. \& Vaiyapuri, M. 2012. Effect of luteolin on lipid peroxidation and antioxidants in acute and chronic periods of isoproterenol induced myocardial infarction in rats Journal of Acute Medicine 2(3): 70-76.

Madhesh, M., Revathi, R. \& Vaiyapuri, M. 2011 Cardioprotective effect of fenugreek on isoproterenolinduced myocardial infarction in rats. Indian Journal of Pharmacology 43(5): 516-519.

Maniam, S., Mohamed, N., Shuid, A.N. \& Soelaiman, I.N. 2008. Palm tocotrienol exerted better antioxidant activities in bone than $\alpha$-tocopherol. Basic and Clinical Pharmacology and Toxicology 103(1): 55-60.

Marney, L.C., Kolwicz Jr., S.C., Tian, R. \& Synovec, R.E. 2013. Sample preparation methodology for mouse heart metabolomics using comprehensive two-dimensional gas chromatography coupled with time-of-flight mass spectrometry. Talanta 108: 123-130.

McCarthy, M.T., Moncayo, G., Hiron, T.K., Jakobsen, N.A., Valli, A., Soga, T., Adam, J. \& O'Callaghan, C.A. 2018. Purine nucleotide metabolism regulates expression of the human immune ligand MICA. Journal of Biological Chemistry 293(11): 3913-3924.

MIMS. 2019. Isoprenaline. https://www.mims.com/malaysia/ drug/info/isoprenaline?mtype=generic Accessed on February 12, 2019. 
Mitra, A., Basak, T., Ahmad, S., Datta, K., Datta, R., Sengupta, S. \& Sarkar, S. 2015. Comparative proteome profiling during cardiac hypertrophy and myocardial infarction reveals altered glucose oxidation by differential activation of pyruvate dehydrogenase E1 component subunit $\beta$. Journal of Molecular Biology 427(11): 2104-2120.

Moffatt, B.A. \& Ashihara, H. 2002. Purine and pyrimidine nucleotide synthesis and metabolism. The Arabidopsis Book 1: $\mathrm{e} 0018$.

Murugesan, M., Revathi, R. \& Manju, V. 2011. Cardioprotective effect of fenugreek on isoproterenol-induced myocardial infarction in rats. Indian Journal of Pharmacology 43(5): 516-519.

Nam, M., Jung, Y., Ryu, D.H. \& Hwang, G.S. 2017. A metabolomics-driven approach reveals metabolic responses and mechanisms in the rat heart following myocardial infarction. International Journal of Cardiology 227: 239246.

Ng, L.T. \& Ko, H.J. 2012. Comparative effects of tocotrienolrich fraction, $\alpha$-tocopherol and $\alpha$-tocopheryl acetate on inflammatory mediators and nuclear factor kappa B expression in mouse peritoneal macrophages. Food Chemistry 134(2): 920-925.

Panda, S., Kar, A. \& Biswas, S. 2017. Preventive effect of agnucastoside $\mathrm{C}$ against isoproterenol-induced myocardial injury. Scientific Reports 7(1): 16146.

Park, S., Page, G.P., Kim, K., Allison, D.B., Meydani, M., Weindruch, R. \& Prolla, T.A. 2008. $\alpha$ - and $\gamma$-Tocopherol prevent age-related transcriptional alterations in the heart and brain of mice. The Journal of Nutrition 138(6): 10101018.

Poloni, S., Blom, J.H. \& Schwartz, V.I. 2015. Stearoyl-CoA desaturase-1: Is it the link between sulfur amino acids and lipid metabolism? Biology 4(2): 383-396.

Prudova, A., Bauman, Z., Braun, A., Vitvitsky, V., Lu, S.C. \& Banerjee, R. 2006. S-adenosylmethionine stabilizes cystathionine beta-synthase and modulates redox capacity. Proceedings of the National Academy of Sciences 103(17): 6489-6494.

Qiu, F., Zhang, H., Yuan, Y., Liu, Z., Huang, B., Miao, H., Liu, X., Zhao, Q., Zhang, H., Dong, H. \& Zhang, Z. 2018. A decrease of ATP production steered by PEDF in cardiomyocytes with oxygen-glucose deprivation is associated with an AMPK-dependent degradation pathway. International Journal of Cardiology 257: 262-271.

Riera-Borrull, M., Garcia-Heredia, A., Fernandez-Arroyo, S., Hernandez-Aguilera, A., Cabre, N., Cuyas, E., LucianoMateo, F., Camps, J., Menendez, J.A. \& Joven, J. 2017. Metformin potentiates the benefits of dietary restraint: A metabolomic study. International Journal of Molecular Sciences 18(11): 2263.

Saito, Y., Yoshida, Y., Nishio, K., Hayakawa, M. \& Niki, E. 2004. Characterization of cellular uptake and distribution of vitamin E. Annals of the New York Academy of Sciences 1031: 368-375.

Sanchis-Gomar, F., Perez-Quilis, C., Leischik, R. \& Lucia, A. 2016. Epidemiology of coronary heart disease and acute coronary syndrome. Annals of Translational Medicine 4(13): 256-256.

Seong, A.C. \& John, C.K.M. 2016. A review of coronary artery disease research in Malaysia. Medical Journal Malaysia 71: 42-57.

Serbinova, E., Kagan, V., Han, D. \& Packer, L. 1991. Free radical recycling and intramembrane mobility in the antioxidant properties of alpha-tocopherol and alpha-tocotrienol. Free Radical Biology \& Medicine 10(5): 263-275.

Siddiqui, M.A., Ahmad, U., Khan, A.A., Ahmad, M., Badruddeen, Khalid, M. \& Akhtar, J. 2016. Isoprenaline: A tool for inducing myocardial infarction in experimental animals. International Journal of Pharmacy 6(2): 138-144.

Singhal, A. \& Cheng, C.Y. 2019. Host NAD ${ }^{+}$Metabolism and infections: Therapeutic implications. International Immunology 31(2): 59-67.

Suvagandha, D., Nishijo, M., Swaddiwudhipong, W., Honda, R., Ohse, M., Kuhara, T., Nakagawa, H. \& Ruangyuttikarn, W. 2014. A biomarker found in cadmium exposed residents of Thailand by metabolome analysis. International Journal of Environmental Research and Public Health 11(4): 36613677.

Thygesen, K., Alpert, J.S., Jaffe, A.S., Simoons, M.L., Chaitman, B.R. \& White, H.D. 2012. Third universal definition of myocardial infarction. European Heart Journal 33(20): 2551-2567.

Top, A. \& Gapor, M. 2005. Production of Palm-Based Tocotrienols-Enhanced Fraction. Kuala Lumpur: Malaysian Palm Oil Board.

Ukachukwu, V., Idris, S. \& Mcllwee, A. 2012. Acute myocardial infarction in a young patient with hyperhomocysteinaemia. BMJ Case Reports 2012: bcr2012007489.

Viana, L.R., Canevarolo, R., Luiz, A.C.P., Soares, R.F., Lubaczeuski, C., de Mattos Zeri, A.C. \& Gomes-Marcondes, M.C.C. 2016. Leucine-rich diet alters the ${ }^{1} \mathrm{H}-\mathrm{NMR}$ based metabolomic profile without changing the Walker-256 tumour mass in rats. BMC Cancer 16(1): 764.

Vlaanderen, J.J., Janssen, N.A., Hoek, G., Keski-Rahkonen, P., Barupal, D.K., Cassee, F.R., Gosens, I., Strak, M., Steenhof, M., Lan, Q., Brunekreef, B., Scalbert, A. \& Vermeulen, R.C.H. 2017. The impact of ambient air pollution on the human blood metabolome. Environmental Research 156: 341-348.

Voegele, A.F., Jerković, L., Wellenzohn, B., Eller, P., Kronenberg, F., Liedl, K.R. \& Dieplinger, H. 2002. Characterization of the vitamin E-binding properties of human plasma afamin. Biochemistry 41(49): 14532-14538.

Wang, L.L., Xie, L., Zhang, Q., Cai, X., Tang, Y., Wang, L.L., Hang, T., Liu, J., Gong, J., Simmons, J.D. \& Gillespie, M.N. 2015. Plasma nuclear and mitochondrial DNA levels in acute myocardial infarction patients. Coronary Artery Disease 26(4): 296-300.

Whitmer, J.T., Idell-Wenger, J.A., Rovetto, M.J. \& Neely, J.R. 1978. Control of fatty acid metabolism in ischemic and hypoxic hearts. Journal of Biological Chemistry 253(12): 4305-4309.

World Health Organization. 2017. Cardiovascular diseases (CVDs): Fact sheet. http://www.who.int/mediacentre/ factsheets/fs317/en/. Accessed on December 12, 2018.

Wu, G., Fang, Y.Z., Yang, S., Lupton, J.R. \& Turner, N.D. 2004. Glutathione metabolism and its implications for health. The Journal of Nutrition 134(3): 489-492.

Zainalabidin, S., Aziz, N.F., Mohd, N.N. \& Jubri, Z. 2018. Effect of palm tocotrienol rich fraction on oxidative status of heart in a rat model of isoprenaline-induced myocardial injury. Research Updates in Medical Sciences 6(1): $1-10$.

Zarkasi, K.A., Jen-Kit, T. \& Jubri, Z. 2019. Molecular understanding of the cardiomodulation in myocardial infarction and the mechanism of Vitamin E protection. Mini Reviews in Medicinal Chemistry 19(17): 1407-1426. 
Zhao, S., Murugiah, K., Li, N., Li, X., Xu, Z.H., Li, J., Cheng, C., Mao, H., Downing, N.S., Krumholz, H.M. \& Jiang, L.X. 2017. Admission glucose and in-hospital mortality after acute myocardial infarction in patients with or without diabetes: A cross-sectional study. Chinese Medical Journal 130(7): 767-775.

Khairul Anwar Zarkasi, Tan Jen-Kit, Nur Haleeda Hakimi \& Zakiah Jubri*

Department of Biochemistry

Faculty of Medicine

UKM Medical Centre

Universiti Kebangsaan Malaysia

Jalan Yaacob Latif, Bandar Tun Razak

56000 Kuala Lumpur, Federal Territory

Malaysia

Satirah Zainalabidin

Programme of Biomedical Science

Centre for Health and Applied Sciences

Faculty of Health Sciences

Universiti Kebangsaan Malaysia

Jalan Raja Muda Abdul Aziz

50300 Kuala Lumpur, Federal Territory

Malaysia
Nur Zuliani Ramli

Department of Anatomy, Faculty of Medicine

UKM Medical Centre

Universiti Kebangsaan Malaysia

Jalan Yaacob Latif, Bandar Tun Razak

56000 Kuala Lumpur, Federal Territory

Malaysia

Khairul Anwar Zarkasi \& Nur Zuliani Ramli

Department of Biomedical Sciences and Therapeutics

Faculty of Medicine and Health Sciences

Universiti Malaysia Sabah, Jalan UMS

88400 Kota Kinabalu, Sabah

Malaysia

*Corresponding author; email: zakiah.jubri@ppukm.ukm.edu. my

Received: 12 May 2019

Accepted: 24 October 2019 
